\section{Timing of Axillary Staging}

\section{TO THE EDITOR}

Optimal timing of axillary staging in patients with locally advanced breast cancer undergoing neoadjuvant chemotherapy remains a contentious issue among surgical oncologists. Our group at the University of Michigan reported a comprehensive approach of staging the axilla prior to chemotherapy (CTX) using a combination of ultrasound, fine-needle aspiration biopsy, and sentinel lymph node biopsy. ${ }^{1}$ The utility of these procedures, in our opinion, is threefold, and will be addressed below.

From a purely clinical perspective, it has been well documented that physical examination of the axilla is notoriously inaccurate. ${ }^{2,3}$ Confirmation of axillary disease prior to CTX is a key point in therapeutic decision making, and at the time of diagnosis, it may solidify the decision to proceed with neoadjuvant CTX altogether. Moreover, as shown by our data and others, use of adjuvant nodal and postmastectomy radiation may reduce local recurrence rates in those patients whose axillae are downstaged by CTX. ${ }^{1,4,5}$ These patients may not be offered these therapies if the axilla is assessed after completion of CTX.

Moreover, as discussed in our publication, there is prognostic utility to obtaining axillary status prior to initiation of CTX. Other authors have shown a prognostic benefit in both overall and disease-free survival in patients with no residual axillary disease after CTX..$^{6-8}$ In our series, axillary response to CTX was inversely correlated with distant relapse. ${ }^{1}$ The implications of this finding may impact not only the immediate adjuvant setting, but longterm decision making as well.

Furthermore, in this dawn of molecular diagnostics, an additional advantage of prechemotherapy axillary biopsy is the availability of untreated, metastatic tumor tissue for banking and correlative testing. As tailored therapy becomes the buzzword for therapeutics in all arenas, the availability of tumor for appropriate studies may be an invaluable resource for the patients involved.

Dr Batsis and colleagues do raise an extremely valid point regarding the time and cost efficacy of prechemotherapy axillary staging. ${ }^{9}$ Clearly, there are additional temporal and financial costs associated with both ultrasound-guided FNA and sentinel node biopsy. The
Comprehensive Breast Program at Moffitt Cancer Center in conjunction with a health care economist has an ongoing study examining these exact issues. We hope to have preliminary results from those analyses in the coming year.

M. Catherine Lee, $\mathrm{MD}^{\mathbf{1}}$, and Kandice E. Kilbride, $\mathrm{MD}^{\mathbf{2}}$ ${ }^{1}$ Surgical Oncology, Comprehensive Breast Program, Moffitt Cancer Center, Tampa, FL;

${ }^{2}$ Breast Cancer Alliance of North Texas, Texas Health Presbyterial Hospital, Dallas, TX

e-mail: kekilbride1@yahoo.com

Published Online: 6 February 2009

(C) Society of Surgical Oncology 2009

\section{REFERENCES}

1. Kilbride K, Lee M, Nees A, Cimmino VM, Diehl KM, Sabel MS, et al. Axillary staging prior to neoadjuvant chemotherapy for breast cancer: predictors of recurrence. Ann Surg Oncol. 2008;15(11):3252-8.

2. Specht MC, Fey JV, Borgen PI, Cody Iii HS. Is the clinically positive axilla in breast cancer really a contraindication to sentinel lymph node biopsy? J Am Coll Surg. 2005;200(1):10-4.

3. Lanng C, Hoffmann J, Galatius H, Engel U. Assessment of clinical palpation of the axilla as a criterion for performing the sentinel node procedure in breast cancer. Eur J Surg Oncol. 2007;33(3):281-4.

4. Buchholz TA, Lehman CD, Harris JR, Pockaj BA, Khouri N, Hylton NF, et al. Statement of the science concerning locoregional treatments after preoperative chemotherapy for breast cancer: a National Cancer Institute conference. $J$ Clin Oncol. 2008;26(5):791-7.

5. McGuire SE, Gonzalez-Angulo AM, Huang EH, Tucker SL, Kau $\mathrm{SW}, \mathrm{Yu} \mathrm{TK}$, et al. Postmastectomy radiation improves the outcome of patients with locally advanced breast cancer who achieve a pathologic complete response to neoadjuvant chemotherapy. Intl J Rad Onc Biol Phys. 2007;68(4):1004-9.

6. Cox CE, Cox JM, White LB, Stowell NG, Clark JD, N Allred, et al. 2006 Sentinel node biopsy before neoadjuvant chemotherapy for determining axillary status and treatment prognosis in local advanced breast cancer. Ann Surg Oncol. 13(4):483-90.

7. Kuerer HM, Sahin AA, Hunt KK, Newman LA, Breslin TM, Ames FC, et al. Incidence and impact of documented eradication of breast cancer axillary lymph node metastasis before surgery in patients treated with neoadjuvant chemotherapy. Ann Surg. 1999;230(1):72-8.

8. Rouzier R, Extra JM, Klijanienko, Falcou MC, Asselain B, VincentSalomon A, et al. (2002) Incidence of prognostic significance of complete axillary downstaging after primary chemotherapy in breast cancer patients with $\mathrm{T} 1$ to $\mathrm{T} 3$ tumors and cytologically proven axillary metastatic lymph nodes. J Clin Oncol. 20(5):1304-10.

9. Batsis C, Ziogas D, Fatouros M. Neoadjuvant chemotherapy for breast cancer: does pretreatment axillary nodal staging improve decision making? Ann Surg Oncol. 2009 (in press). Doi:10.1245/ s10434-009-0351-6. 